\title{
Comparative effects of six probiotic strains on immune function in vitro
}

\author{
Honglin Dong, Ian Rowland and Parveen Yaqoob* \\ Department of Food and Nutritional Sciences, The University of Reading, Whiteknights, PO Box 226, Reading RG6 6AP, UK
}

(Submitted 19 January 2011 - Final revision received 14 September 2011 - Accepted 20 September 2011 - First published online 7 November 2011)

\begin{abstract}
There is considerable interest in the strain specificity of immune modulation by probiotics. The present study compared the immunomodulatory properties of six probiotic strains of different species and two genera in a human peripheral blood mononuclear cell (PBMC) model in vitro. Live cells of lactobacilli (Lactobacillus casei Shirota, L. rhamnosus GG, L. plantarum NCIMB 8826 and L. reuteri NCIMB 11951) and bifidobacteria (Bifidobacterium longum SP $07 / 3$ and B. bifidum MF 20/5) were individually incubated with PBMC from seven healthy subjects for $24 \mathrm{~h}$. Probiotic strains increased the proportion of $\mathrm{CD} 69^{+}$on lymphocytes, T cells, T cell subsets and natural killer (NK) cells, and increased the proportion of $\mathrm{CD}_{2} 5^{+}$, mainly on lymphocytes and NK cells. The effects on activation marker expression did not appear to be strain specific. NK cell activity was significantly increased by all six strains, without any significant difference between strains. Probiotic strains increased production of IL- $1 \beta$, IL-6, IL-10, TNF- $\alpha$, granulocyte-macrophage colony-stimulating factor and macrophage inflammatory protein $1 \alpha$ to different extents, but had no effect on the production of IL- 2 , IL- 4 , IL- 5 or TNF- $\beta$. The cytokines that showed strain-specific modulation included IL-10, interferon- $\gamma$, TNF- $\alpha$, IL-12p70, IL-6 and monocyte chemotactic protein-1. The Lactobacillus strains tended to promote T helper 1 cytokines, whereas bifidobacterial strains tended to produce a more anti-inflammatory profile. The results suggest that there was limited evidence of strain-specific effects of probiotics with respect to $\mathrm{T}$ cell and NK cell activation or NK cell activity, whereas production of some cytokines was differentially influenced by probiotic strains.
\end{abstract}

\section{Key words: Cytokines: Immune function: Probiotics: Lymphocytes}

Lactobacilli and bifidobacteria are the most common species used as probiotics in the food industry ${ }^{(1)}$. Probiotics are well known for their role in preventing and treating acute gastrointestinal infections, allergy and atopic diseases and inflammatory bowel diseases ${ }^{(2)}$. However, the mechanisms by which probiotic bacteria elicit their effects are not fully understood. There is considerable interest in the modulation of immune function by probiotics. The immune response to probiotics is generally regarded to be strain dependent, with differences proposed to be due to the diverse protein profiles in their cell walls and differing $\mathrm{CpG}$ content of their DNA ${ }^{(3)}$. The beneficial effects of these strains are based partly on their ability to regulate differentially the production of anti- and pro-inflammatory cytokines and $\mathrm{T}$ helper (Th)1/Th2 balance ${ }^{(4-6)}$. Therefore, most in vitro studies examining the effects of probiotics on human immune function have focused on cytokine production, with peripheral blood mononuclear cells (PBMC) being widely used as a cell model. There is some evidence of strain-dependent patterns of cytokine production, even among strains of the same species ${ }^{(7)}$. However, this evidence is limited to a small number of cytokines (chiefly
IL-10, IL-12, TNF- $\alpha$ and interferon (IFN)- $\gamma$ ), and there is little information on the strain specificity of probiotics with respect to other aspects of immune function, particularly cellmediated immunity.

There are some comparative data for effects of probiotics on natural killer (NK) cell activation or activity in vitro. For example, heat-killed Lactobacillus casei Shirota, L. acidophilus ATCC 4356 and Bifidobacterium breve ATCC 15700NK were reported to enhance NK cell activity and induce NK cell activation (CD69 expression on NK cells) in human $\mathrm{PBMC}^{(8)}$; live L. johnsonii La 1 and L. sakei LTH 681 induced CD25 expression on NK cells ${ }^{(9)} ;$ L. reuteri DSM12246, L. acidophilus $\mathrm{X} 37$ and $B$. bifidum S13.1 all increased NK cell activity ${ }^{(10)}$ Also, L. paracasei 11688, L. salivarius 11794 and a commercial mix of the two stimulated a significant increase in $\mathrm{CD} 16^{+} / \mathrm{CD} 56^{+} \mathrm{NK}$ cells ${ }^{(11)}$. This suggests that enhancement of NK cell activity may be a common feature of lactobacilli and bifidobacteria. Some probiotics, for example, L. casei Shirota, have also been shown to increase NK cell activity in human studies, indicating the relevance of these in vitro models to the in vivo situation ${ }^{(12)}$.

Abbreviations: GM-CSF, granulocyte-macrophage colony-stimulating factor; GRO- $\alpha$, growth related oncogene- $\alpha$; IFN, interferon; LPS, lipopolysaccharide; MCP-1, monocyte chemotactic protein-1; MFI, mean fluorescence intensity; MIP-1, macrophage inflammatory protein 1; MRS, de Man, Rogosa and Sharpe; NK, natural killer; PBMC, peripheral blood mononuclear cell; RANTES, regulated on activation normal T cell-expressed and secreted; RPMI, Roswell Park Memorial Institute; Tc, T cytotoxic; Th, T helper; WC, Wilkins-Chalgren.

*Corresponding author: P. Yaqoob, fax +44 118931 0080, email p.yaqoob@reading.ac.uk 
$\mathrm{T}$ lymphocyte activation markers and $\mathrm{T}$ cell proliferation are commonly used parameters to assess immune function ${ }^{(13)}$. Kankaanpaa et al. ${ }^{(14)}$ demonstrated that several different probiotic homogenates (L. rhamnosus GG, L. rhamnosus LC-705, L. acidophilus, B. animalis ssp. lactis BB-12, L. delbrueckii ssp. bulgaricus, Streptococcus thermophilus T101 and Propionibacterium JS) inhibited both basal and phytohaemagglutininstimulated PBMC proliferation in vitro. Moreover, Lactobacillus GG, B. animalis ssp. lactis BB-12 and L. acidophilus homogenates inhibited the expression of CD25, CD69 and human leucocyte antigen-DR (HLA-DR) on phytohaemagglutininstimulated $\mathrm{T}$ lymphocytes. These findings suggest that specific probiotic bacteria, or factors derived from them, may provide down-regulatory signals for PBMC. However, other studies indicated that some probiotic strains up-regulated T cell or dendritic cell activation markers. For example, Castellazzi et al. ${ }^{(11)}$ reported that L. paracasei I 1688, L. salivarius I 1794 and a commercial mix of the two induced a significant increase in $\mathrm{CD}^{+} / \mathrm{CD} 25^{+}$cells (Th-activated regulatory cells) and $\mathrm{CD}^{+} / \mathrm{CD} 25^{+}$cells (T-suppressor/cytotoxic-activated cells), which may be useful in improving adaptive cell immune responses. Zeuthen et al. ${ }^{(15)}$ reported that some human gut flora-derived lactic acid bacteria ${ }^{(4)}$, which are strong IL-12 and TNF- $\alpha$ inducers, enhanced surface markers CD40, CD83, CD86 and HLA-DR by human dendritic cells.

The aim of the present study was to investigate the effect of six probiotic strains of different species, and from two genera, on a wide spectrum of cytokines, on T cell and NK cell activation and on NK cell activity in a single in vitro model.

\section{Materials and methods}

\section{Bacterial strains and culture conditions}

The bacterial strains examined in the present study and their suppliers included $L$. casei Shirota (isolated from Yakult fermented milk), L. rhamnosus GG (ATCC 53103), L. plantarum NCIMB 8826 (NCIMB, Aberdeen, Scotland), L. reuteri NCIMB 11951 (NCIMB), B. longum SP 07/3 and B. bifidum MF 20/5 (both Bifidobacterium strains were isolated and confirmed by $16 \mathrm{~S}$ rDNA sequencing from Bion-3 (Tokyo, Japan)). Lactobacillus strains were grown in de Man, Rogosa and Sharpe (MRS) agar or broth (Oxoid, Hampshire, UK) and Bifidobacterium strains in Wilkins-Chalgren (WC) agar or broth (Oxoid). The bacterial strains were grown on MRS/WC agar for $48 \mathrm{~h}$ ( $72 \mathrm{~h}$ for Bifidobacterium strains). For liquid culture, one isolated colony was taken from an MRS/WC agar plate and grown overnight in $10 \mathrm{ml}$ of pre-reduced MRS/WC broth (Oxoid) with 0.05\% L-cysteine hydrochloride (Sigma, Dorset, UK) in a shaking incubator (Cooled Orbital Incubator, Gallenkamp, Loughborough, UK) at $37^{\circ} \mathrm{C}$, and $0.5 \mathrm{ml}$ of the overnight culture was inoculated into another $10 \mathrm{ml}$ MRS broth. The bacteria were harvested in the exponential phase, resuspended in PBS (Oxoid), centrifuged twice at $1960 \mathrm{~g}$ (Sanyo/MSE Micro Centaur, Haverhill, MA, USA) for $5 \mathrm{~min}$ and resuspended at the required concentration in Roswell Park Memorial Institute (RPMI) 1640 (Autogen Bioclear, Wiltshire, UK) containing $0.75 \mathrm{~mm}$-glutamine (Autogen Bioclear).

\section{Preparation of peripheral blood mononuclear cells}

Fasted blood samples were taken from seven healthy donors aged 58-65 years, in Na heparin vacutainer tubes (Greiner Bio-One Limited, Gloucestershire, UK). The present study was conducted according to the guidelines laid down in the Declaration of Helsinki, and all procedures involving human subjects were approved by the Ethics Committee of the Reading University. Written informed consent was obtained from all subjects. Blood was layered over an equal volume of Lympholyte (Cedarlane Laboratories Limited, Burlington, Ontario, Canada) and centrifuged at $930 \mathrm{~g}$ for $15 \mathrm{~min}$ at room temperature. The plasma was removed into a sterile tube for later use. Cells were harvested from the interface, washed once, resuspended in RPMI 1640 medium (containing glutamine) and the afore-mentioned steps were then repeated to achieve a lower degree of erythrocyte contamination. The pellet was finally resuspended in RPMI and the cell number was adjusted to the required concentration.

\section{In vitro culture conditions}

PBMC, adjusted to $2 \times 10^{6}$ cells $/ \mathrm{ml}$, were incubated in twenty-four-well plates in the presence of six probiotic strains separately or in $1 \mu \mathrm{g} / \mathrm{ml}$ lipopolysaccharide (LPS; L4516, Sigma) and $2.5 \%$ autologous plasma for $24 \mathrm{~h}$ at $37^{\circ} \mathrm{C}$ in an air $-\mathrm{CO}_{2}(19: 1)$ atmosphere. The ratio of PBMC and bacteria was 1:1. At the end of the incubation, cells were stained for activation marker measurement, and supernatants were collected and stored at $-20^{\circ} \mathrm{C}$ for later analysis of cytokine production. Non-stimulated cultures were used as negative controls.

\section{Lymphocyte activation analysis}

Cells were stained with appropriate combinations of fluorescently labelled mouse anti-human monoclonal antibodies for discrimination between different lymphocyte subsets. The expression of the activation markers, CD69 and CD25, on the following lymphocyte subsets was assessed: $\mathrm{T}$ lymphocytes $\left(\mathrm{CD}^{+}\right)$, Th cells $\left(\mathrm{CD}^{+} \mathrm{CD}^{+}\right)$, cytotoxic $\mathrm{T}$ cells (Tc; $\mathrm{CD}^{+} \mathrm{CD}^{+}$) and $\mathrm{NK}$ cells $\left(\mathrm{CD} 3^{-} \mathrm{CD} 56^{+}\right)$. Monoclonal antibodies were conjugated to fluorescein isothiocyanate, phycoerythrin or phycoerythrin-Cy5. PBMC were incubated with fluorescently labelled monoclonal antibodies (all from BD Biosciences, Franklin Lakes, NJ, USA) for $30 \mathrm{~min}$ at $4^{\circ} \mathrm{C}$ in the dark and washed by Cell Wash (BD Biosciences) twice before fixing with Cell Fix (BD Biosciences). The fixed cells were run on a Becton Dickinson FACSCalibur flow cytometer (BD Biosciences) within $24 \mathrm{~h}$. The lymphocytes were gated and fluorescence data for 10000 events were collected using Becton Dickinson CellQuest software (BD Biosciences, Franklin Lakes, NJ, USA). Phenotypical results were expressed as both the percentage of CD69- or CD25-positive cells and CD69 or CD25 mean fluorescence intensity (MFI) within a particular cell subset. Data were analysed by Flowjo software v 7.6.1 (Tree Star, Inc., Ashland, OR, USA). 


\section{Cytokine analysis in cell culture supernatants}

Cytokines were preliminarily screened by a semi-quantitative method to simultaneously detect the relative levels of thirtysix different cytokines and chemokines (C5a, CD40 ligand, granulocyte colony-stimulating factor, granulocyte-macrophage colony-stimulating factor (GM-CSF), growth related oncogene (GRO) $-\alpha$, chemokine (C-C motif) ligand 1, intracellular adhesion molecule-1 (IAM-1), IFN- $\gamma$, IL- $1 \alpha$, IL-1 $\beta$, IL-1ra, IL-2, IL-4, IL-5, IL-6, IL-8, IL-10, IL-12p70, IL-13, IL-16, IL-17, IL-17E, IL-23, IL-27, IL-32 $\alpha$, interferon $\gamma$-induced protein $10 \mathrm{kDa}$ (IP-10), interferon inducible T-cell alpha chemoattractant (I-TAC), monocyte chemotactic protein-1 (MCP-1), macrophage migration inhibitory factor (MIF), macrophage inflammatory protein 1 (MIP-1) $\alpha$, MIP-1 $\beta$, regulated on activation normal $\mathrm{T}$ cell-expressed and secreted (RANTES), strotromal cell-derived factor 1 (SDF-1), plasminogen activator inhibitor 1 (PAI-1), TNF- $\alpha$ and triggering receptor expressed on myeloid cells-1 (TREM-1) using the Human Cytokine Array Kit (R\&D Systems, Minneapolis, MN, USA). In the present screening experiment, four samples were tested: an unstimulated control, PBMC stimulated with LPS (positive control), PBMC co-cultured with $L$. case Shirota and PBMC co-cultured with B. longum SP 07/3. Briefly, culture supernatants were incubated with the specific capture and detection antibodies on a nitrocellulose membrane at $2-8^{\circ} \mathrm{C}$ on a rocking platform overnight. After washing, streptavidin-horseradish peroxidase was added and after 30-min incubation, the nitrocellulose membrane was exposed to enhanced chemiluminescence reagents (GE Healthcare UK Limited, Buckinghamshire, UK) for $2 \mathrm{~min}$. Membranes were exposed to hyperfilm for $2 \mathrm{~min}$ in an autoradiographic cassette and developed for $5 \mathrm{~min}$ in the dark. Protein spots were quantified using Quantity One v4 software (Bio Rad, Hertfordshire, UK).

A total of thirteen cytokines were selected for quantitative analysis using a multiplex system by flow cytometry, on the basis of the initial screening process described earlier. The Human Th1/Th2 11plex Kit (Bender Medsystems, Vienna, Austria) was used to measure IFN- $\gamma$, IL-1 $\beta$, IL-2, IL-4, IL-5, IL-6, IL-8, IL-10, IL-12 p70, TNF- $\alpha$ and TNF- $\beta$. MCP-1 and MIP-1 $\alpha$ simplex kits (Bender Medsystems) were added to the human 11 plex kit. The detection limit of the cytokine/chemokine assays was as follows: IFN- $\gamma, 1.6 \mathrm{pg} / \mathrm{ml}$ IL- $1 \beta$, $4.2 \mathrm{pg} / \mathrm{ml} ; \mathrm{IL}-2,16.4 \mathrm{pg} / \mathrm{ml} ; \mathrm{IL}-5,1.6 \mathrm{pg} / \mathrm{ml} ; \mathrm{IL}-6,1.2 \mathrm{pg} / \mathrm{ml}$; IL-8, $0.5 \mathrm{pg} / \mathrm{ml}$; IL-10, $1.9 \mathrm{pg} / \mathrm{ml}$; IL-12 (p70), $1.5 \mathrm{pg} / \mathrm{ml} ;$ TNF$\alpha, 3.2 \mathrm{pg} / \mathrm{ml} ;$ TNF- $\beta, 2.4 \mathrm{pg} / \mathrm{ml} ;$ MCP- $1,2 \cdot 2 \mathrm{pg} / \mathrm{ml} ; \mathrm{MIP}-1 \alpha$, $1.0 \mathrm{pg} / \mathrm{ml}$; GM-CSF, $3.4 \mathrm{pg} / \mathrm{ml}$ and RANTES, $25 \mathrm{pg} / \mathrm{ml}$. Analysis was conducted according to the manufacturer's instructions. FlowCytomixTM Pro 2.3 Software (Bender Medsystems) was used to perform the data analysis. Concentrations of GM-CSF and RANTES in the cell culture supernatants were measured by ELISA (Bender Medsystems) according to the manufacturer's instructions.

\section{Natural killer cell activity}

Freshly prepared PBMC were incubated for $24 \mathrm{~h}$ in the presence of medium alone or individual probiotic strain. The PBMC concentration was adjusted to $5 \times 10^{6}$ cells $/ \mathrm{ml}$. Viable target cells (K562) were enumerated by microscopy of trypan blue-stained cell preparations, and $5 \times 10^{6}$ cells were collected and washed twice with PBS before incubation with carboxyfluorescein diacetate succinimidyl ester (CFDA-SE) $\left(1 \mu \mathrm{g} / \mathrm{ml}\right.$; Sigma) for $45 \mathrm{~min}$ at $37^{\circ} \mathrm{C}$ in an air- $\mathrm{CO}_{2}(19: 1)$ atmosphere. After incubation, the target cells were washed twice and resuspended in $1 \mathrm{ml}$ of complete medium composed of RPMI 1640 medium, $0.75 \mathrm{~mm}$-glutamine and $10 \%$ newborn calf serum (Sigma). PBMC were incubated with CFDA-SE labelled target cells for $2 \mathrm{~h}$ at $37^{\circ} \mathrm{C}$ in an air- $\mathrm{CO}_{2}$ (19:1) atmosphere at effector to target cell ratios of 50:1 and 25:1. A measure of $20 \mu \mathrm{l}$ of propidium iodide (PI) (Sigma) at $1 \mathrm{mg} / \mathrm{ml}$ was added to the samples before analysis on the flow cytometer. The results were expressed as the percentage lysis of the target cells. Flowjo software v 7.6.1 (Tree Star, Inc., Ashland, OR, USA) was used to perform the data analysis.

\section{Statistics}

Data are presented as means with their standard errors. All data were analysed using SPSS version 15.0 (IBM Corporation, New York, USA). Significant differences among treatments were evaluated by one-way ANOVA by post hoc $t$ tests with Bonferroni correction. Correlations between two variables were analysed by using Pearson's correlation coefficients. The criterion for statistical significance was defined as $P<0 \cdot 05$.

\section{Results}

After $24 \mathrm{~h}$ incubation of PBMC with probiotics, the viability of PBMC was measured by trypan blue. The viability was 91\% with medium, 57\% with L. casei Shirota, 36\% with $L$. rhamnosus GG, 53\% with L. plantarum NCIMB 8826, $42 \%$ with $L$. reuteri NCIMB 11951, 49\% B. longum SP $07 / 3$ and $74 \%$ with $B$. bifidum MF 20/5. Although there were differential effects of probiotics on the viability of PBMC, the effects of probiotics on activation markers and NK cell activity were assessed in viable cells only, as non-viable cells were eliminated during gating. Differences in viability may, however, have an influence on cytokine/chemokine production.

\section{Effect of six probiotic strains on the expression of activation markers}

The expression of two activation markers, CD69 and CD25, by lymphocytes, T cells, T cell subsets and NK cells was assessed in non-stimulated PBMC (negative control) and PBMC stimulated by six different probiotic bacterial strains. The results are shown as the proportion of $\mathrm{CD} 69^{+}$or $\mathrm{CD} 25^{+}$cells (\%) and the MFI in the specific cell group.

All probiotic strains significantly increased expression of both CD69 and CD25 by lymphocytes, except for L. rhamnosus GG which did not significantly increase expression of CD25 (\%; Fig. 1(b)). All strains, except for L. casei Shirota and L. rhamnosus GG, significantly increased the MFI of CD69 and CD25 on lymphocytes (Fig. 1(c)). In addition, L. plantarum NCIMB 8826 and L. reuteri NCIMB 11951 had a greater effect on CD69 expression (MFI) than L. rhamnosus GG (Fig. 1(c)). 

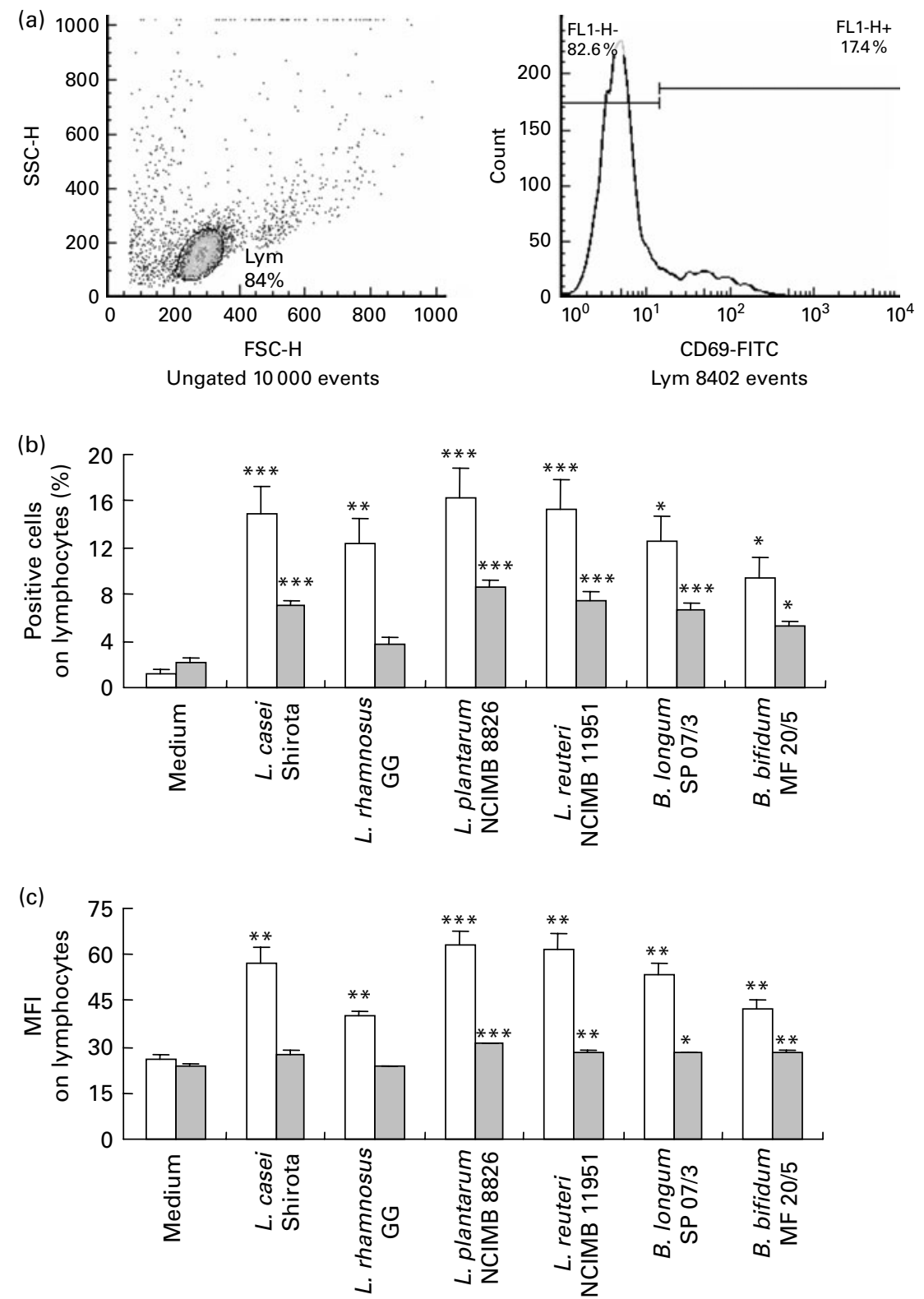

Fig. 1. Effects of probiotic strains on expression of activation markers on lymphocytes. Values are means with their standard errors represented by vertical bars. Peripheral blood mononuclear cells from seven volunteers were incubated with one of six live probiotic strains for $24 \mathrm{~h}$. (a) Gating strategy for flow cytometry. Expression of the activation markers, CD69 ( $\square$ ) and CD25 ( $\square$ ), are shown as (b) \% positive cells and (c) mean fluorescence intensity (MFI). Mean values were significantly different from those of control (medium only): ${ }^{\star} P<0.05,{ }^{\star \star} P<0.01,{ }^{\star \star \star} P<0.001$ (post hoc $t$ tests with Bonferroni correction). SSC-H, side scatter height; Lym, lymphocyte; FSC-H, forward scatter height; FL1-H, first fluorescence detector height; FITC, fluorescein isothiocyanate; L., Lactobacillus; B., Bifidobacterium.

All strains tended to increase CD69 expression (both percentage and MFI) by $\mathrm{T}$ cells $\left(\mathrm{CD}^{+}{ }^{+}\right.$, comprising $78 \%$ of lymphocytes), but in some cases this did not reach statistical significance (Table 1). None of the probiotic strains affected the expression of CD69 (either percentage or MFI) by $\mathrm{CD}^{+} \mathrm{CD}^{+}$Th cells (comprising $51 \%$ of lymphocytes), except for $L$. reuteri NCIMB 11951, which significantly increased CD69 expression (\%) by Th cells (Table 1). All six strains increased the proportion of $\mathrm{CD} 69^{+}$cells in the $\mathrm{CD} 3^{+} \mathrm{CD} 8^{+} \mathrm{Tc}$ cell subset (comprising $27 \%$ of lymphocytes), although only the effects of the L. casei Shirota, L. plantarum NCIMB 8826, L. reuteri NCIMB 11951 and B. longum SP 07/3 reached statistical significance for MFI of CD69 expression (Table 1). There was no effect of any probiotic strain on CD25 expression by T cells, Th or Tc cells, except for L. plantarum NCIMB 8826, which significantly induced CD25 MFI by those cells (Table 1). Overall, the results suggest that there is preferential activation of Tc cells by probiotics to some degree.

The gating strategy for $\mathrm{NK}$ cells $\left(\mathrm{CD} 56^{+} \mathrm{CD} 3^{-}\right)$is shown in Fig. 2. NK cells comprise approximately $15 \%$ of lymphocytes. All six strains significantly increased CD69 and CD25 expression (\%) by NK cells (range from 57.55 to $82.52 \%$ and 8.08 to $22.26 \%$, respectively). Some of them also significantly increased MFI of CD69 or CD25 expression on this population (Table 2). These results suggest that probiotics enhance activation of the NK cells, without any obvious strain specificity. 


\section{Probiotics stimulate natural killer cell activity}

NK cell activity was assessed in PBMC after $24 \mathrm{~h}$ incubation with medium or each of the probiotic strains. The gating strategy is shown in Fig. 3(a). At a 50:1 ratio of effector cells (PBMC) to target cells (K562 cells), NK cell activity was increased from $11.2 \%$ of specific lysis to $38 \cdot 3-42 \cdot 3 \%$ by the six strains, with no significant difference between them (Fig. 3(b)). At the lower ratio of 25:1, only $L$. casei Shirota and the two bifidobacterial strains, B. longum SP $07 / 3$ and B. bifidum MF 20/5 significantly increased NK cell activity (Fig. 3(b)).

\section{Effect of six probiotic strains on production of cytokines by peripheral blood mononuclear cells}

Initially, a human cytokine proteome profiler array was employed to screen the effects of one strain of Lactobacillus (L. casei Shirota) and one strain of Bifidobacterium (B. longum SP 07/3) on relative levels of thirty-six cytokines and chemokines in cell culture supernatants in order to identify the cytokines that were most significantly subject to modulation by probiotics for further detailed study. Supernatants from PBMC cultured in medium only or in the presence of LPS were screened as negative and positive controls. LPS induced production of GM-CSF, GRO- $\alpha$, IL-1 $\beta$, IL-6, IL-8, IL-1ra, MCP-1, MIP-1 $\alpha$, RANTES and TNF- $\alpha$. Both probiotic strains also induced the production of these cytokines, but they additionally induced production of IFN- $\gamma, \mathrm{C} 5 \mathrm{a}$ and IL- $1 \alpha$. LPS was a better inducer of GRO- $\alpha$, IL-6, IL-1ra, MIP-1 $\alpha$ and MCP-1, while the two probiotic strains induced more IL- 8 , IL-1 $\beta$ and TNF- $\alpha$ than LPS. The main difference between the two strains regarding their capacity to induce cytokine production were that $L$. case $i$ Shirota induced more C5a, GM-CSF and RANTES, but less IL-6, MIP-1 $\beta$ and MCP-1 than B. longum SP $07 / 3$ (data not shown). There was no obvious effect of LPS or probiotic strains on the production of other cytokines.

The quantitative measurement of cytokine production was largely consistent with the results of the proteome profiler array. The effects of the six probiotic strains on production of fifteen cytokines and chemokines in total were assessed using flow cytometry or ELISA. The production of four of the cytokines selected (IL-2, IL-4, IL-5 and TNF- $\beta$ ) was undetectable in both unstimulated and stimulated culture supernatants, whereas IL-8 and RANTES production was detected at much higher levels even in unstimulated cultures $(3166.3$ and $55.8 \mathrm{pg} / \mathrm{ml}$, respectively). All strains increased the production of IL-1 $\beta$, IL-6, IL-10, TNF- $\alpha$, GM-CSF and MIP- $1 \alpha$ to different extents (Fig. 4). IFN- $\gamma$ production was stimulated by all strains except for L. rbamnosus GG. IL-12 production was only significantly increased by $L$. casei Shirota and L. plantarum NCIMB 8826 (Fig. 4). MCP-1 production was only induced by the Bifidobacterium strains (Fig. 4). In addition, the pattern for IL-10 production showed that the two Bifidobacterium strains and LPS tended to induce more IL-10 production than Lactobacillus strains (Fig. 4). All strains, except for $L$. reuteri NCIMB 11951, induced more IL-1 $\beta$ and TNF- $\alpha$ production than LPS. Overall, Lactobacillus strains 

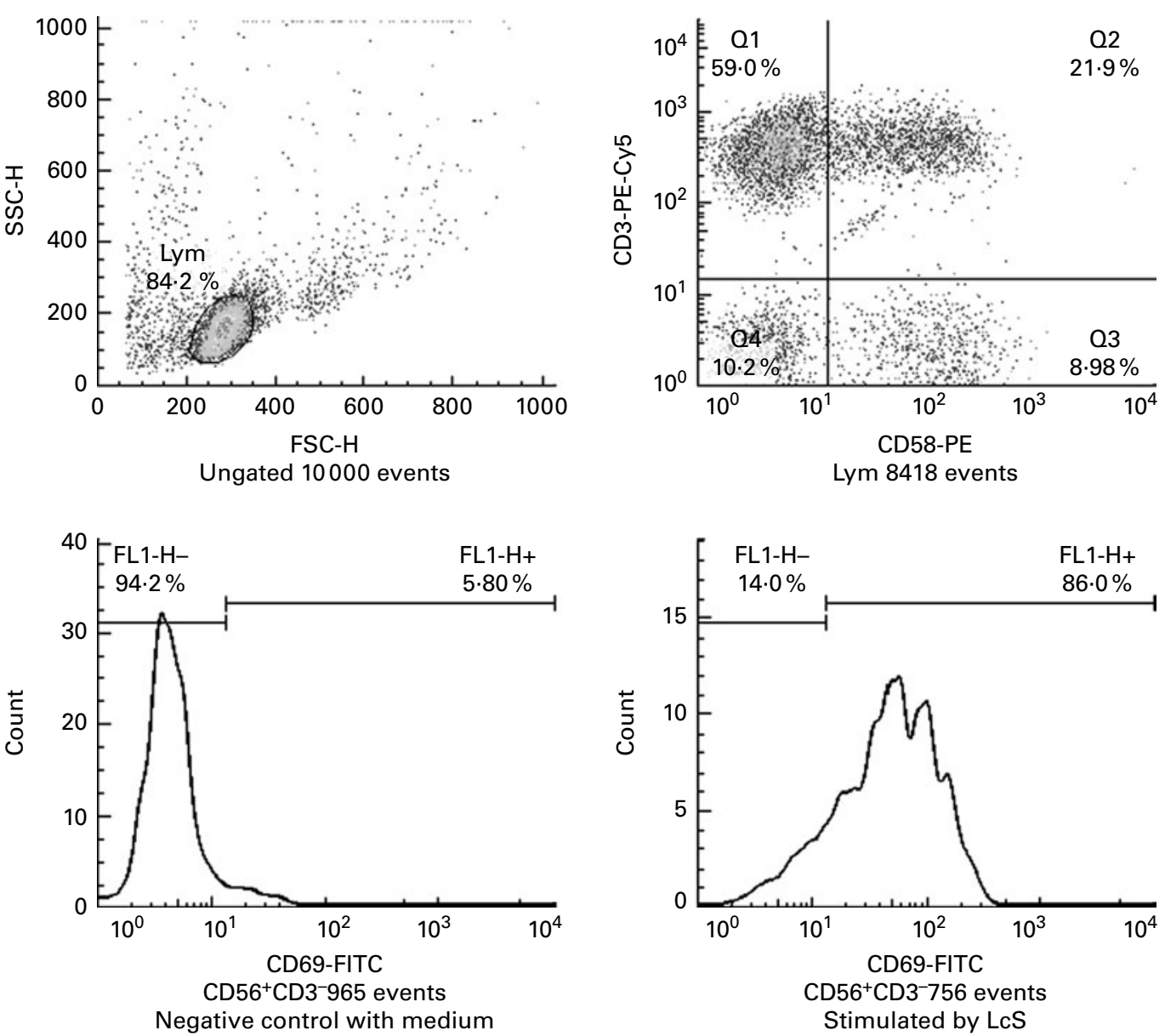

Fig. 2. Gating strategy for natural killer cells $\left(\mathrm{CD} 6^{+} \mathrm{CD}{ }^{-}\right)$and their activation marker expression. SSC-H, side scatter height; Lym, lymphocyte; FSC-H, forward scatter height; FL1-H, first fluorescence detector height; FITC, fluorescein isothiocyanate; LcS, L. casei Shirota.

were good inducers of IL-12 (apart from L. rhamnosus GG), whereas Bifidobacterium strains were better inducers of IL10, IL-6 and MCP-1. Additionally, L. casei Shirota was a good inducer of GM-CSF, IL-12 and IFN- $\gamma$, and L. rhamnosus GG induced comparable levels of IL-8, IL-1 $\beta$ and RANTES to other strains, but lower levels of all other tested cytokines. L. plantarum NCIMB 8826 and L. reuteri NCIMB 11951 had very similar cytokine profiles, except that $L$. plantarum NCIMB 8826 induced the highest level of IL-12, whereas $L$. reuteri NCIMB 11951 was the best inducer of IFN- $\gamma$. Regarding the two bifidobacterial strains, B. longum SP $07 / 3$ was a good inducer of IFN- $\boldsymbol{\gamma}$, whereas B. bifidum MF 20/5 was a good inducer of GM-CSF.

When the cytokine profiles were expressed as ratios of key cytokines, IL-10:IL-12 and TNF- $\alpha$ :IL-10, distinct patterns emerged for lactobacilli and bifidobacterial strains (Fig. 5). Bifidobacterial strains, in particular B. bifidum MF 20/5, produced a high ratio of IL-10:IL-12, whereas Lactobacillus strains tended to produce a high ratio of TNF- $\alpha$ :IL-10 (Fig. 5).

\section{Discussion}

The health-promoting properties of probiotics are suggested to be strain dependent; therefore, strain identification and characterisation are very important ${ }^{(16)}$. Probiotics elicit their functions in different ways, among which immunomodulation is suggested to be one of the most important mechanisms ${ }^{(17)}$. Our previous study with $L$. casei Shirota $^{(18)}$ in vitro showed that $L$. case $i$ Shirota promoted NK cell activity, preferentially induced expression of $\mathrm{CD} 69$ and $\mathrm{CD} 25$ on $\mathrm{CD}^{+}$and $\mathrm{CD} 56^{+}$ subsets and induced significant production of IL-1 $\beta$, IL- 6 , TNF- $\alpha$, IL-12 and IL-10 by PBMC. On the basis of the aforementioned results, we conducted the present study to comparatively investigate the immunomodulation by six different probiotic strains including $L$. casei Shirota using human PBMC as an in vitro model. Although this model is not fully reflective of the in vivo situation in which intestinal bacteria interact with Peyer's patches, communicate with $\mathrm{M}$ cells resident in the epithelium ${ }^{(19)}$ and interact directly with dendritic cells, macrophages and $\mathrm{T}$ cells ${ }^{(5)}$, several studies suggest that an in vitro PBMC model is useful as a screening tool to identify characteristic traits of probiotic strains and to select probiotic strains for clinical trials ${ }^{(5-7,17,20)}$. For example, probiotic strains displaying in vitro potential to induce higher levels of the anti-inflammatory cytokine, IL-10, and lower levels of the pro-inflammatory cytokine, IL-12, offered the best protection in a murine model of acute 2,4,6-trinitrobenzenesulfonic acid (TNBS) colitis in vivo ${ }^{(21)}$. The probiotic strains that 
Table 2. Activation of natural killer cells by different probiotic strains $\dagger$

(Mean values with their standard errors)

\begin{tabular}{|c|c|c|c|c|c|c|c|c|}
\hline \multirow[b]{4}{*}{ Treatment } & \multicolumn{8}{|c|}{$\mathrm{CD}_{56}{ }^{+} \mathrm{CD}^{-}$} \\
\hline & \multicolumn{4}{|c|}{ Positive (\%) } & \multicolumn{4}{|c|}{ MFI } \\
\hline & \multicolumn{2}{|c|}{ CD69 } & \multicolumn{2}{|c|}{ CD25 } & \multicolumn{2}{|c|}{ CD69 } & \multicolumn{2}{|c|}{ CD25 } \\
\hline & Mean & SE & Mean & $\mathrm{SE}$ & Mean & SE & Mean & SE \\
\hline Medium & 3.80 & 0.56 & 0.18 & 0.04 & 27.00 & 1.38 & 18.98 & 1.95 \\
\hline L. casei Shirota & $78 \cdot 68^{\star \star \star}$ & 3.87 & $21 \cdot 18^{\star \star \star}$ & 1.67 & $60 \cdot 27^{\star \star}$ & $5 \cdot 71$ & $24 \cdot 28$ & 0.52 \\
\hline L. rhamnosus GG & $61 \cdot 42^{\star \star}$ & $6 \cdot 16$ & $8.08^{*}$ & 1.09 & $41 \cdot 15$ & 1.63 & $21 \cdot 10$ & 0.51 \\
\hline L. plantarum NCIMB 8826 & $79 \cdot 95^{\star \star \star}$ & 3.24 & $20 \cdot 58^{\star \star \star}$ & 2.63 & $67 \cdot 55^{\star \star \star}$ & $6 \cdot 69$ & 23.52 & 0.55 \\
\hline L. reuteri NCIMB 11951 & $82 \cdot 52^{\star \star \star}$ & 2.85 & $19 \cdot 40^{\star \star}$ & 4.47 & $69 \cdot 53^{\star \star \star}$ & $9 \cdot 87$ & 21.86 & 1.33 \\
\hline B. longum SP $07 / 3$ & $75 \cdot 93^{\star \star *}$ & $4 \cdot 17$ & $22 \cdot 26^{\star \star \star}$ & 2.85 & $59 \cdot 17^{*}$ & $6 \cdot 89$ & $25 \cdot 54^{\star}$ & 0.72 \\
\hline B. bifidum MF $20 / 5$ & $57 \cdot 55^{\star \star}$ & $5 \cdot 81$ & $11.49^{*}$ & 2.76 & 42.47 & 4.41 & $25 \cdot 06^{*}$ & 0.72 \\
\hline
\end{tabular}

MFI, mean fluorescence intensity; L., Lactobacillus; B., Bifidobacterium.

Mean values were significantly different from those of medium-only control: ${ }^{*} P<0.05$, ${ }^{\star *} P<0.01$, ${ }^{\star * *} P<0.001$ (post hoc $t$ tests with Bonferroni correction).

†Peripheral blood mononuclear cells from seven volunteers were incubated with one of six live probiotic strains for $24 \mathrm{~h}$. Expression of

the activation markers, CD69 and CD25, are shown as \% positive cells and MFI for natural killer cells $\left(\mathrm{CD}_{56}{ }^{+} \mathrm{CD}^{-}\right)$.

induced both IL-10 and IFN- $\gamma$ by spleen cells from naive or Par $\mathrm{j}$ 1-sensitised mice in vitro resulted in a significant reduction in serum-specific IgG1 and markedly reduced IL13 and IL-4 mRNA expression, but increased IL-10 expression in vivo ${ }^{(22)}$. Therefore, the results from the present study may be useful in extrapolating to in vivo studies and for making predictions about the potential clinical uses of probiotics, even though some studies do not show consistency between in vitro and in vivo results ${ }^{(23,24)}$.

CD69 and CD25 are cellular molecules whose expression can be induced on T cells, B cells, NK cells and other cells by stimulation with pathogens during inflammation or by mitogens ${ }^{(25)}$. Therefore, their surface expression can be used to assess the activation of lymphocytes ${ }^{(13)}$. There is very limited information

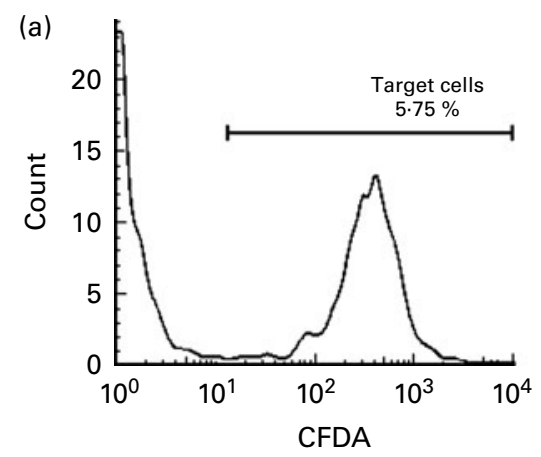

Ungated 10000 events

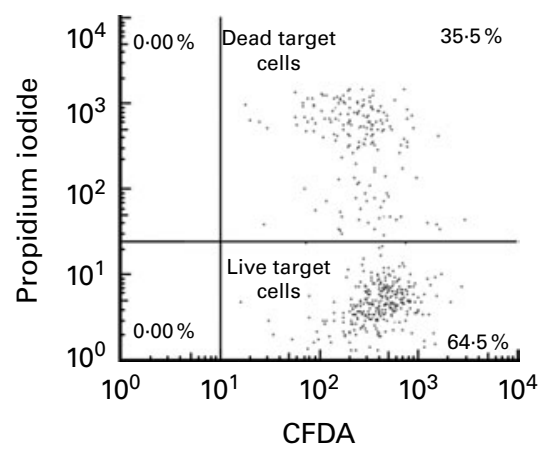

Target cells 575 events

(b)

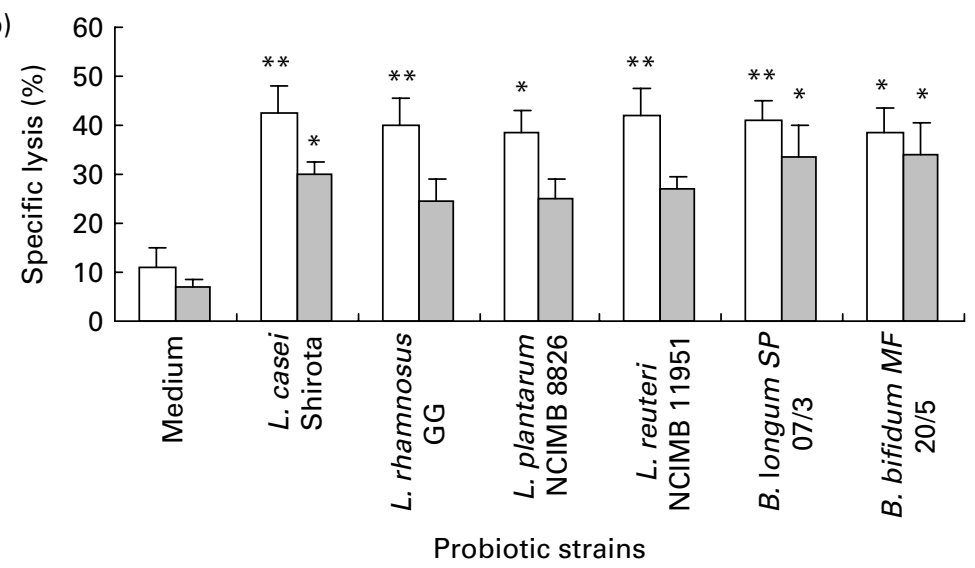

Fig. 3. Effect of probiotics on natural killer (NK) cell activity. Values are means with their standard errors represented by vertical bars. Peripheral blood mononuclear cells from six volunteers were incubated with one of six live probiotic strains for $24 \mathrm{~h}$. NK cell activity was measured as the percentage lysis of target cells (K562 cells). (a) Gating strategy for flow cytometry. (b) The impact of probiotic strains on NK cell activity. $\square$, Effector/target $(E / T)=50 ; \square, E / T=25$. Mean values were significantly different from those of control: ${ }^{\star} P<0.05,{ }^{\star *} P<0.01$ (post hoc $t$ tests with Bonferroni correction). CFDA, carboxyfluorescein diacetate; L., Lactobacillus; B., Bifidobacterium. 

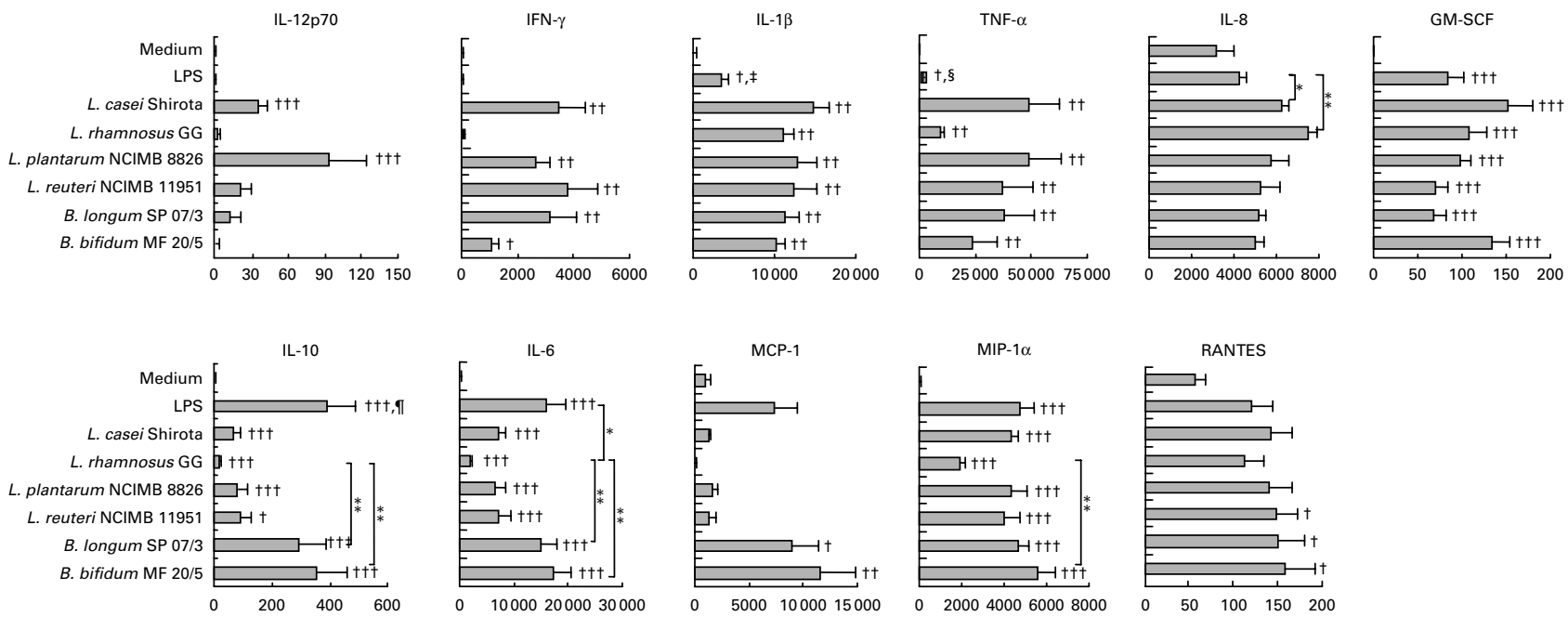

Fig. 4. Effect of six probiotic strains on cytokine production by peripheral blood mononuclear cells (PBMC). Values are means with their standard errors (pg/ml) represented by horizontal bars. PBMC from seven volunteers were incubated with one of six live probiotic strains for $24 \mathrm{~h}$. Cytokines in unstimulated and stimulated cell culture supernatants were analysed by a multiple fluorescent bead-based immunoassay or by ELISA. Mean values were significantly different: ${ }^{*}<<0.05$, ${ }^{\star *} P<0.01$. Mean values were significantly different from those of control: $\dagger P<0.05, \dagger \dagger P<0.01,+\dagger \dagger P<0.001$ (post hoc $t$ tests with Bonferroni correction). $\ddagger$ Mean values of IL-1 $\beta$ were significantly different from those of all strains except for Lactobacillus $(L$.) reuteri NCIMB $11951(P<0.05$; post hoc $t$ tests with Bonferroni correction). $\S$ Mean values of TNF- $\alpha$ were significantly different from those of all strains except for $L$. reuteri NCIMB 11951 ( $P<0.05$; post hoc $t$ tests with Bonferroni correction). I Mean values of IL-10 were significantly different from those of four $L$. strains $(P<0.05$; post hoc $t$ tests with Bonferroni correction). LPS, lipopolysaccharide; B., Bifidobacterium; IFN- $\gamma$, interferon $\gamma$; GM-CSF, granulocyte-macrophage colony-stimulating factor; MCP-1, monocyte chemotactic protein-1; MIP-1 $\alpha$, macrophage inflammatory protein $1 \alpha$; RANTES, regulated on activation normal T cell-expressed and secreted.

regarding strain-specific effects of probiotics on cellular immunity. In the present study, we investigated the effect of six probiotic strains from different species on the expression of CD69 and CD25 by specific lymphocyte subsets. There was some evidence of preferential activation of $\mathrm{CD} 8^{+} \mathrm{T}$ cells by all the strains, as they all increased expression of CD69 by this subset. In a previous in vitro study ${ }^{(18)}, L$. casei Shirota was found to preferentially activate the $\mathrm{CD}^{+}$cell population. In fact, this appears to be a common feature of several probiotics and is supported by data from human intervention studies. For example, in a human trial by Meyer et $\mathrm{al}^{(26)}$, the expression of CD69 by T lymphocytes was increased by consumption of both conventional yogurt and a probiotic product, and this activation was especially significant in the $\mathrm{CD} 8^{+}$subset, with a lesser effect on $\mathrm{CD}^{+}$lymphocytes. In a randomised, placebo-controlled human trial ${ }^{(27)}$, the effect of Saccharomyces boulardii administration was studied in healthy children aged between 6 months and 10 years, who were admitted for acute diarrhoea. The patients who were supplemented with S. boulardii for $7 \mathrm{~d}$ showed a significant decrease in daily stool frequency and a significant increase in the percentage of $\mathrm{CD}^{+}$lymphocytes and serum IgA, compared with the placebo group. In a randomised, double-blind, placebo-controlled intervention study by de Vrese et $a l .^{(28)}, 479$ healthy adults were supplemented with $L$. gasseri PA 16/8, B. longum SP $07 / 3$ and B. bifidum MF 20/5 for 3 months. Cellular immune parameters were evaluated in a randomly drawn subgroup of 122 volunteers before and after $14 \mathrm{~d}$ of supplementation. The results showed that the total symptom score, the duration of common cold episodes and days with fever during an episode were significantly lower, and there was a significant enhancement in the percentage of Tc suppressor cells $\left(\mathrm{CD}^{+}\right)$after the probiotic supplement. Overall, therefore, several strands of evidence suggest that probiotics preferentially enhance the activation of cytotoxic lymphocytes $\left(\mathrm{CD} 8^{+}\right)$.

NK cells are a component of the non-specific immune response involved in destroying tumour cells and virusinfected cells ${ }^{(29)}$. Our previous ${ }^{(18)}$ and another in vitro study $^{(8)}$ showed that L. casei Shirota promotes CD69 expression on NK cells and enhances NK cell activity in human PBMC. The present study showed that all of the tested probiotic strains enhanced activation of all NK cell subsets and elicited similar capacity to stimulate NK cell activity, without showing any strain-specific properties. This property of probiotic strains has been confirmed by some human studies, in which oral consumption of $L$. casei Shirota ${ }^{(12)}$, L. fermentum CECT5716 30 , L. paracasei NCC $2461^{(31)}$ or L. rhamnosus HNO01 enhanced NK cell activity in healthy adult or elderly population. However, some human studies did not show any effect of probiotic strains on NK cell
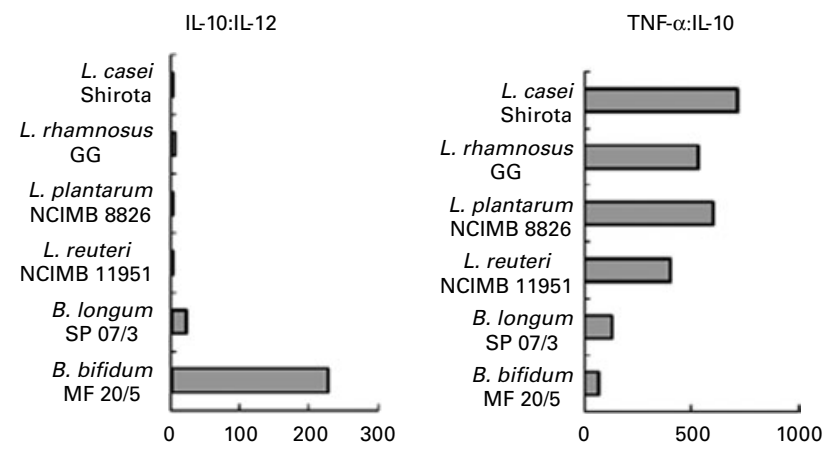

Fig. 5. Effect of six probiotic strains of different species on ratios of key cytokines. The ratios were calculated by the mean of each treatment. L., Lactobacillus; B., Bifidobacterium. 
$\operatorname{activity}^{(32,33)}$, perhaps due to differences in sample size, probiotic dose, consumption period, study design and status of volunteers and so on. Some human studies also showed that consumption of the mixture of $L$. gasseri PA $16 / 8, B$. longum SP $07 / 3$ and $B$. bifidum MF $20 / 5$ reduced the total symptom score and the duration of common cold episodes ${ }^{(28)}$; consumption of L. fermentum CECT5716 reduced the incidence of an influenza-like illness during 5 months after vaccination ${ }^{(30)}$; and consumption of L. fermentum VRI-003 (PCC) substantially decreased the number of days and severity of respiratory infection in a cohort of highly trained distance runners ${ }^{(34)}$. In addition, an epidemiological study indicated that consumption of $L$. case $i$ probiotic strain for 4 years by subjects who were presently free from tumour and who had had at least two colorectal tumours removed significantly reduced the occurrence rate of tumours with moderate atypia or higher grade compared to the control group ${ }^{(35)}$.

In the present study, there were some notable strain-specific differences regarding the activation marker, although these were limited. For example, there was no effect of probiotic strains on activation of Th cells, except that $L$. plantarum NCIMB 8826; L. rhamnosus GG and B. bifidum MF 20/5 tended to show the weakest effect on activation on different cell groups.

Several studies investigating the effects of probiotics on immune function have focused on the Th1/Th2 or pro-inflammatory/anti-inflammatory cytokine balance ${ }^{(17,20,36)}$. Th1 cells produce IL- 2 , IFN- $\gamma$ and TNF- $\alpha$, which activate Tc and macrophages to stimulate cellular immunity against intracellular pathogens such as viruses, raise the classic delayed-type hypersensitivity skin response to viral and bacterial antigens, promote inflammation and respond to cancer cells. Th1 cells also secrete IL-3 and GM-CSF to stimulate the bone marrow to produce more leucocytes. Th2 cells secrete IL-4, IL-5, IL-9, IL-13 and IL-31, which stimulate allergenspecific IgE by B cells and tissue inflammation characterised by the influx of eosinophils/mast cells and activated $\mathrm{CD}^{+}{ }^{+} \mathrm{T}$ cells $^{(37)}$. In addition, the regulatory $\mathrm{T}$ cell population secretes anti-inflammatory cytokines, such as IL-10 and transforming growth factor- $\beta$, and can potentially suppress IgE production and Th1/Th2 proliferation ${ }^{(37)}$. More recently, a new Th17 sub-population that secretes IL-17 has been identified. IL-17 is a pro-inflammatory cytokine, which is suppressed by Th1derived IFN- $\gamma$ and Th2-derived IL- ${ }^{(38)}$. However, imbalance of the pathways is related to some diseases. For example, overreaction of the Th1 or Th17 pathway can generate organ-specific autoimmune disease (e.g. arthritis, multiple sclerosis and type 1 diabetes), whereas a shift to Th2 contributes to allergic diseases and predisposes to systematic autoimmune disease ${ }^{(39)}$.

Probiotics clearly modulate cytokine production, and the effects appear to be strain specific to some degree ${ }^{(40)}$. Generally, most strains are capable of inducing TNF- $\alpha^{(4,7,21,41-43)}$ and IL- $6^{(17,44)}$, which might be a common response of PBMC to any bacterial stimuli. It is generally accepted that Lactobacillus strains are able to induce pro-inflammatory cytokines, such as IL-12 and IFN- $\gamma$, as well as anti-inflammatory cytokines, such as IL-10 ${ }^{(45)}$, whereas Bifidobacterium strains are usually better inducers of IL-10 than Lactobacillus strains $^{(41,46)}$. The results of the present study support this view, as they demonstrate that strains of B. longum SP 07/3 and B. bifidum MF 20/5, as well as LPS, were good inducers of IL-10, whereas Lactobacillus strains were not. However, some studies have shown that not all Bifidobacterium strains stimulate more IL-10 production than Lactobacillus strains ${ }^{(17)}$, and, in fact, there is considerable difference even between different Bifidobacterium species for their ability to induce IL- $10^{(7,47)}$. This appeared to be the case in the present study, in which ratios of IL-10:IL-12 after incubation with B. longum SP $07 / 3$ or B. bifidum MF $20 / 5$ were significantly different from one another, as well as being different from the effects of the Lactobacillus strains.

The capacity of probiotic bacteria to induce cytokine production in human leucocyte cell culture is usually characterised by either the Th1 type or the anti-inflammatory direction in a manner specific to the bacterial genera ${ }^{(24)}$. It might be expected that the probiotic strains that shift towards production of Th1 cytokines could be useful in the prevention or treatment of atopic disease ${ }^{(48)}$, whereas strains that induce large amounts of anti-inflammatory cytokines, such as IL-10, could be useful in the treatment of inflammatory diseases, such as ulcerative colitis, pouchitis and rheumatoid arthritis ${ }^{(41)}$. However, the strains that induce anti-inflammatory cytokines, such as IL-10 and transforming growth factor- $\beta$, are actually regarded to be favourable in the prevention or treatment of atopic disease ${ }^{(48,49)}$. In the present study, we examined the effects of six probiotic strains on production of fifteen cytokines or chemokines. All strains significantly increased the production of IL-1 $\beta$, IL-6, IL-10, TNF- $\alpha$, GM-CSF and MIP-1 $\alpha$, although to different extents, whereas none of them induced production of IL-2, IL-4, IL-5 or TNF- $\beta$. The cytokines that showed strain-specific modulation included IL-10, IFN- $\gamma$, TNF- $\alpha$, IL-12 and MCP-1. This strainspecific effect on induction of cytokines, except for MCP-1, was also observed in other in vitro or in vivo studies ${ }^{(7,20,50)}$. All strains in the present study simultaneously induced both pro-inflammatory (IL-1 $\beta$, IL-6, TNF- $\alpha$, GM-CSF and MIP- $1 \alpha$ ) and anti-inflammatory (IL-10) cytokines, whereas only L. casei Shirota and L. plantarum NCIMB 8826 induced Th1 cytokine IL-12, and all tested strains, except for L. rhamnosus GG, induced the Th1 cytokine, IFN- $\gamma$. It is worthy to note that T cells are not the only cell type to respond to probiotic stimulants to produce cytokines. Antigen-presenting cells, including dendritic cells, monocytes and B cells, in PBMC also contribute to significant cytokine induction by probiotics within a short time after stimulation. Expressing results as ratios of key cytokines, such as IL-10:IL-12 and TNF- $\alpha$ :IL-10, represents a practical way of interpreting the data ${ }^{(17)}$. The balance of IL-10:IL-12 production is crucial for determination of the direction of the immune response ${ }^{(51)}$. IL-10 and IL-12 are secreted by dendritic cells, monocytes or macrophages in response to bacterial products, but have largely opposite effects on the immune system ${ }^{(45)}$. IL-12 is a key cytokine promoting Th1 responses by stimulating $\mathrm{T}$ cells and NK cells to secrete IFN- $\gamma$, which is essential for successful defence against intracellular pathogen infections, whereas IL-10 down-regulates 
the inflammatory response and induces an antibody-mediated immune response ${ }^{(17,41)}$. Therefore, the IL-10:IL-12 ratio is used as an indicator for Th1:Th2 balance. The results from the present study indicate that both bifidobacterial strains, but in particular B. bifidum MF $20 / 5$, resulted in a higher ratio of IL-10:IL-12 than all Lactobacillus strains, indicating the potential to offer protection against in vivo colitis and potentially atopic disease. IL-10 and TNF- $\alpha$ are pleiotropic cytokines that are produced by both $\mathrm{T}$ lymphocytes and monocytes, but they play opposite roles in inflammatory responses, and therefore their relative balance is of central relevance for controlling immune deviation ${ }^{(17)}$. The results from the present study indicate that all the tested Lactobacillus strains, but not Bifidobacterium strains, increased the ratio of TNF- $\alpha: I L-10$, indicating a potential Th1 polarisation and enhancement of cellular immunity. L. casei Shirota, a strain from commercial fermented milk, has been reported to induce IL-12, IFN- $\gamma$, TNF- $\alpha$ and IL-10 in the present study and in an in vitro human PBMC model ${ }^{(8)}$, to promote NK cell activity both in vitro and in a human study ${ }^{(8,12)}$ and to modulate immune responses in allergic rhinitis in a human study ${ }^{(52)}$. Moreover, the immunomodulatory effect of $L$. casei Shirota has also been supported by microarray analysis in an animal model, in which L. casei Shirota enhanced the gene expression involving defence/immune functions with more strength than B. breve Yakult ${ }^{(53)}$. Although $L$. casei Shirota is regarded as an inducer of Th1 or pro-inflammatory cytokine production, some animal studies indicated that $L$. casei Shirota consumption was able to improve some diseases that are thought to be partly driven by Th1 or pro-inflammatory orientation. For example, a study in an animal model demonstrated that L. casei Shirota did not exacerbate experimental autoimmune encephalomyelitis, and in fact tended to suppress the development of neurological symptoms ${ }^{(54)}$. Another animal study showed that $L$. casei Shirota inhibited the synthesis of IL-6 in LPS-stimulated large intestinal lamina propria mononuclear cells in vitro and the diet with $L$. casei Shirota improved murine colitis with repression of IL- 6 synthesis by large intestinal lamina propria mononuclear cells ${ }^{(55)}$. These indicate that probiotic strains regulate rather than simply stimulate immune function, depending on the target population and their condition of inflammation, by mechanisms that are still poorly understood. L. rhamnosus GG is another well-documented commercial probiotic strain that is regarded as anti-inflammatory. Supporting evidence shows that consumption of L. rhamnosus GG reduces levels of serum C-reactive protein, decreases $S$. pyogenes-stimulated TNF- $\alpha$ production ${ }^{(24)}$, inhibits LPS-stimulated TNF- $\alpha$ production and reduces TNF- $\alpha$ :IL-10 ratios in a murine macrophage model ${ }^{(56)}$, induces the anti-inflammatory cytokine IL-10 ex vivo in human subjects ${ }^{(57)}$ and has been reported to be effective in alleviating symptoms of atopic diseases $^{(58-60)}$. Interestingly, L. rhamnosus GG showed poor induction of IL-12, IFN- $\gamma$, IL-10, MCP-1 and IL-6 and a higher ratio of TNF- $\alpha$ :IL-10 (indicating a Th1-favoured response) in the present study and also in some other in vitro studies ${ }^{(6,41)}$. However, cytokine induction is only one of the proposed mechanisms of action for probiotics. Other important factors may be contributors to the effects of probiotics in vivo; for example, the ability to adhere to the gut epithelium, to promote non-immunological gut defence barrier by normalising permeability, to improve gut microecology and to enhance gut-specific IgA responses ${ }^{(61)}$. Moreover, although some studies demonstrate that L. casei Shirota ${ }^{(52)}$ and L. rhamnosus GG had beneficial effects in atopic disease ${ }^{(52,58-60)}$, there are also some studies showing no effect of $L$. casei Shirota in animal models $^{(62)}$ and of L. rhamnosus GG in human studies ${ }^{(37,63)}$; hence, there is still some inconsistency in the area.

Monocytes appear to be essential for at least some of the immunomodulatory effects of probiotics. In an in vitro study $^{(8)}$, L. casei Shirota was shown to be phagocytosed by monocytes and directly stimulated them to secrete not only pro-inflammatory cytokines, such as IL-12 and TNF- $\alpha$, but also the anti-inflammatory cytokine, IL-10. Our previous study also showed that monocyte depletion significantly reduced the impact of $L$. casei Shirota on NK cell activity, lymphocyte activation and cytokine induction ${ }^{(18)}$.

To our knowledge, the present study is the first to compare the effects of probiotic strains from different species on chemokine production by human PBMC. All of the strains shared a similar ability to induce IL- 8, MIP- $1 \alpha$ and RANTES, but variable abilities to induce MCP-1. MCP-1 is a CC chemokine and is expressed by monocytes, dendritic cells, vascular endothelial cells and other cell types in response to the cytokines IL-1, TNF- $\alpha$, IFN- $\gamma$, as well as bacterial or viral products and mitogens. MCP-1 exhibits chemotactic activity for monocytes/macrophages, basophils, $\mathrm{T}$ lymphocytes (particularly memory $\mathrm{T}$ cells and NK cells) and neural stem cells ${ }^{(64)}$. In addition to its chemotactic function, MCP-1 also induces the expression of IL-10 from macrophages ${ }^{(64)}$. IL- 6 acts as both a pro-inflammatory and anti-inflammatory cytokine ${ }^{(65)}$. It is secreted by $\mathrm{T}$ cells and macrophages to stimulate immune response to different stimuli, whereas its anti-inflammatory role is exhibited through its inhibitory effects on TNF- $\alpha$ and IL- 1 and activation of IL-1ra and IL- $10^{(65)}$. Interestingly, there was a positive correlation between IL-10, IL-6 and MCP-1 induction after probiotic stimulation in the present study (Table 3), indicating that IL-10 production by probiotic strains may be dependent, to some extent, on the induction of IL-6 and MCP1. However, this needs to be tested with neutralisation antibodies. Ultimately, it would be desirable and valuable to construct a statistical model to identify cytokine profiles for individual probiotic strains and relate these to the intrinsic properties of bacteria in an in vitro screening study. This would require in vitro screening of very large numbers of species/ strains and assessment of a wide range of cytokines.

In conclusion, the present in vitro study demonstrated that there was little evidence of strain-specific effects of six

Table 3. Correlation of $\mathrm{IL}-10$ induction to monocyte chemotactic protein-1 (MCP-1) and IL-6 induction by probiotic strains

\begin{tabular}{llcc}
\hline & MCP-1 & IL-6 \\
\hline IL-10 & Pearson correlation & $\begin{array}{c}0.82 \\
<0.001\end{array}$ & $\begin{array}{c}0.92 \\
<0.001\end{array}$ \\
& Sigma (two-tailed) & $<$ & \\
\hline
\end{tabular}


probiotics on T cell, NK cell activation or NK cell activity. In contrast, cytokine production was differentially influenced by probiotic strains of different species. The biological importance in vivo of these strain-specific effects remains to be determined.

\section{Acknowledgements}

The present research was sponsored by a Dorothy Hodgkin Postgraduate Award and Yakult UK. All authors contributed to the study design, analysis of the data and preparation of the manuscript. The authors declare no conflict of interest.

\section{References}

1. Isolauri E, Salminen S \& Ouwehand AC (2004) Probiotics. Best Pract Res Clin Gastroenterol 18, 299-313.

2. Sleator RD \& Hill C (2008) New frontiers in probiotic research. Lett Appl Microbiol 46, 143-147.

3. Paineau D, Carcano D, Leyer G, et al. (2008) Effects of seven potential probiotic strains on specific immune responses in healthy adults: a double-blind, randomized, controlled trial. FEMS Immunol Med Microbiol 53, 107-113.

4. Cross ML, Ganner A, Teilab D, et al. (2004) Patterns of cytokine induction by gram-positive and gram-negative probiotic bacteria. FEMS Immunol Med Microbiol 42, 173-180.

5. Ghadimi D, Folster-Holst R, de Vrese M, et al. (2008) Effects of probiotic bacteria and their genomic DNA on $\mathrm{T}(\mathrm{H}) 1 /$ $\mathrm{T}(\mathrm{H}) 2$-cytokine production by peripheral blood mononuclear cells (PBMCs) of healthy and allergic subjects. Immunobiology 213, 677-692.

6. Helwig U, Lammers KM, Rizzello F, et al. (2006) Lactobacilli, bifidobacteria and E. coli Nissle induce pro- and antiinflammatory cytokines in peripheral blood mononuclear cells. World J Gastroenterol 12, 5978-5986.

7. Medina M, Izquierdo E, Ennahar S, et al. (2007) Differential immunomodulatory properties of Bifidobacterium logum strains: relevance to probiotic selection and clinical applications. Clin Exp Immunol 150, 531-538.

8. Shida K, Suzuki T, Kiyoshima-Shibata J, et al. (2006) Essential roles of monocytes in stimulating human peripheral blood mononuclear cells with Lactobacillus casei to produce cytokines and augment natural killer cell activity. Clin Vaccine Immunol 13, 997-1003.

9. Haller D, Blum S, Bode C, et al. (2000) Activation of human peripheral blood mononuclear cells by nonpathogenic bacteria in vitro: evidence of NK cells as primary targets. Infect Immun 68, 752-759.

10. Fink LN, Zeuthen LH, Christensen HR, et al. (2007) Distinct gut-derived lactic acid bacteria elicit divergent dendritic cell-mediated NK cell responses. Int Immunol 19, 1319-1327.

11. Castellazzi AM, Valsecchi C, Montagna L, et al. (2007) In vitro activation of mononuclear cells by two probiotics: Lactobacillus paracasei I 1688, Lactobacillus salivarius I 1794, and their mixture (PSMIX). Immunol Invest 36, 413-421.

12. Takeda K \& Okumura K (2007) Effects of a fermented milk drink containing Lactobacillus casei strain Shirota on the human NK-cell activity. J Nutr 137, 791S-793S

13. Albers R, Antoine JM, Bourdet-Sicard R, et al. (2005) Markers to measure immunomodulation in human nutrition intervention studies. Br J Nutr 94, 452-481.

14. Kankaanpaa P, Sutas Y, Salminen S, et al. (2003) Homogenates derived from probiotic bacteria provide down-regulatory signals for peripheral blood mononuclear cells. Food Chem 83, 269-277.

15. Zeuthen LH, Christensen HR \& Frokiaer H (2006) Lactic acid bacteria inducing a weak interleukin-12 and tumor necrosis factor alpha response in human dendritic cells inhibit strongly stimulating lactic acid bacteria but act synergistically with gram-negative bacteria. Clin Vaccine Immunol $\mathbf{1 3}$ 365-375.

16. Salminen S, Collado MC, Isolauri E, et al. (2009) Microbialhost interactions: selecting the right probiotics and prebiotics for infants. Nestle Nutr Workshop Ser Pediatr Program 64 201-217.

17. Lopez P, Gueimonde M, Margolles A, et al. (2010) Distinct Bifidobacterium strains drive different immune responses in vitro. Int J Food Microbiol 138, 157-165.

18. Dong H, Rowland I, Tuohy KM, et al. (2010) Selective effects of Lactobacillus casei Shirota on T cell activation, natural killer cell activity and cytokine production. Clin Exp Immunol 161, 378-388.

19. Hessle C, Hanson LA \& Wold AE (1999) Lactobacilli from human gastrointestinal mucosa are strong stimulators of IL-12 production. Clin Exp Immunol 116, 276-282.

20. Drago L, Nicola L, Iemoli E, et al. (2010) Strain-dependent release of cytokines modulated by Lactobacillus salivarius human isolates in an in vitro model. BMC Res Notes 3 $44-48$.

21. Foligne B, Nutten S, Grangette C, et al. (2007) Correlation between in vitro and in vivo immunomodulatory properties of lactic acid bacteria. World J Gastroenterol 13, 236-243.

22. Mastrangeli G, Corinti S, Butteroni C, et al. (2009) Effects of live and inactivated VSL\#3 probiotic preparations in the modulation of in vitro and in vivo allergen-induced Th2 responses. Int Arch Allergy Immunol 150, 133-143.

23. Flinterman AE, Knol EF, van Ieperen-Van Dijk AG, et al (2007) Probiotics have a different immunomodulatory potential in vitro versus ex vivo upon oral administration in children with food allergy. Int Arch Allergy Immunol 143 237-244.

24. Kekkonen RA, Lummela N, Karjalainen H, et al. (2008) Probiotic intervention has strain-specific anti-inflammatory effects in healthy adults. World $I$ Gastroenterol $\mathbf{1 4}$ 2029-2036.

25. Rea IM, McNerlan SE \& Alexander HD (1999) CD69, CD25, and HLA-DR activation antigen expression on $\mathrm{CD}^{+}$lymphocytes and relationship to serum TNF-alpha, IFN-gamma, and sIL-2R levels in aging. Exp Gerontol 34, 79-93.

26. Meyer AL, Micksche M, Herbacek I, et al. (2006) Daily intake of probiotic as well as conventional yogurt has a stimulating effect on cellular immunity in young healthy women. Ann Nutr Metab 50, 282-289.

27. Ozkan TB, Sahin E, Erdemir G, et al. (2007) Effect of Saccharomyces boulardii in children with acute gastroenteritis and its relationship to the immune response. J Int Med Res 35, 201-212

28. de Vrese M, Winkler P, Rautenberg P, et al. (2005) Effect of Lactobacillus gasseri PA 16/8, Bifidobacterium longum SP $07 / 3$, B. bifidum MF $20 / 5$ on common cold episodes: a double blind, randomized, controlled trial. Clin Nutr $\mathbf{2 4}$, 481-491.

29. Garciapenarrubia P, Koster FT, Kelley RO, et al. (1989) Antibacterial activity of human natural-killer cells. J Exp Med $\mathbf{1 6 9}$, 99-113

30. Olivares M, Diaz-Ropero MP, Sierra S, et al. (2007) Oral intake of Lactobacillus fermentum CECT5716 enhances the effects of influenza vaccination. Nutrition 23, 254-260. 
31. Bunout D, Barrera G, Hirsch S, et al. (2004) Effects of a nutritional supplement on the immune response and cytokine production in free-living Chilean elderly. $J$ Parenter Enter Nutr 28, 348-354.

32. Roller M, Clune Y, Collins K, et al. (2007) Consumption of prebiotic inulin enriched with oligofructose in combination with the probiotics Lactobacillus rhamnosus and Bifidobacterium lactis has minor effects on selected immune parameters in polypectomised and colon cancer patients. Br J Nutr 97, 676-684.

33. Spanhaak S, Havenaar R \& Schaafsma G (1998) The effect of consumption of milk fermented by Lactobacillus casei strain Shirota on the intestinal microflora and immune parameters in humans. Eur J Clin Nutr 52, 899-907.

34. Cox AJ, Pyne DB, Saunders PU, et al. (2010) Oral administration of the probiotic Lactobacillus fermentum VRI-003 and mucosal immunity in endurance athletes. Br J Sports Med 44, 222-226.

35. Ishikawa H, Akedo I, Otani T, et al. (2005) Randomized trial of dietary fiber and Lactobacillus casei administration for prevention of colorectal tumors. Int J Cancer 116, 762-767.

36. de Roock S, van Elk M, van Dijk MEA, et al. (2010) Lactic acid bacteria differ in their ability to induce functional regulatory T cells in humans. Clin Exp Allergy 40, 103-110.

37. Kalliomaki M, Antoine JM, Herz U, et al. (2010) Guidance for substantiating the evidence for beneficial effects of probiotics: prevention and management of allergic diseases by probiotics. J Nutr 140, 713S-721S.

38. Weaver CT, Harrington LE, Mangan PR, et al. (2006) Th17: an effector CD4 T cell lineage with regulatory T cell ties. Immunity 24, 677-688.

39. Singh VK, Mehrotra S \& Agarwal SS (1999) The paradigm of Th1 and Th2 cytokines - its relevance to autoimmunity and allergy. Immunol Res 20, 147-161.

40. Borchers AT, Selmi C, Meyers FJ, et al. (2009) Probiotics and immunity. J Gastroenterol 44, 26-46.

41. Kekkonen RA, Kajasto E, Miettinen M, et al. (2008) Probiotic Leuconostoc mesenteroides ssp cremoris and Streptococcus thermophilus induce IL-12 and IFN-gamma production. World J Gastroenterol 14, 1192-1203.

42. Timmerman HM, Niers LEM, Ridwan BU, et al. (2007) Design of a multispecies probiotic mixture to prevent infectious complications in critically ill patients. Clin Nutr 26, 450-459.

43. Vissers YM, Snel J, Zuurendonk PF, et al. (2010) Differential effects of Lactobacillus acidophilus and Lactobacillus plantarum strains on cytokine induction in human peripheral blood mononuclear cells. FEMS Immunol Med Microbiol 59, 60-70.

44. Miettinen M, VuopioVarkila J \& Varkila K (1996) Production of human tumor necrosis factor alpha, interleukin- 6 , and interleukin-10 is induced by lactic acid bacteria. Infect Immun 64, 5403-5405.

45. Hessle C, Andersson B \& Wold AE (2000) Gram-positive bacteria are potent inducers of monocytic interleukin-12 (IL-12) while gram-negative bacteria preferentially stimulate IL-10 production. Infect Immun 68, 3581-3586.

46. Hart AL, Lammers K, Brigidi $\mathrm{P}$, et al. (2004) Modulation of human dendritic cell phenotype and function by probiotic bacteria. Gut 53, 1602-1609.

47. Lammers KM, Brigidi P, Vitali B, et al. (2003) Immunomodulatory effects of probiotic bacteria DNA: IL-1 and IL-10 response in human peripheral blood mononuclear cells. FEMS Immunol Med Microbiol 38, 165-172.

48. Niers LEM, Timmerman HM, Rijkers GT, et al. (2005) Identification of strong interleukin-10 inducing lactic acid bacteria which down-regulate $\mathrm{T}$ helper type 2 cytokines. Clin Exp Allergy 35, 1481-1489.

49. Ji GE (2009) Probiotics in primary prevention of atopic dermatitis. In Food Factors for Health Promotion, pp. 117-128. Basel: Karger.

50. Clancy RL \& Pang G (2007) Probiotics - industry myth or a practical reality? J Am Coll Nutr 26, 691S-694S.

51. Kaji R, Kiyoshima-Shibata J, Nagaoka M, et al. (2010) Bacterial teichoic acids reverse predominant IL-12 production induced by certain Lactobacillus strains into predominant IL-10 production via TLR2-dependent ERK activation in macrophages. J Immunol 184, 3505-3513.

52. Ivory K, Chambers SJ, Pin C, et al. (2008) Oral delivery of Lactobacillus casei Shirota modifies allergen-induced immune responses in allergic rhinitis. Clin Exp Allergy 38, $1282-1289$.

53. Shima T, Fukushima K, Setoyama H, et al. (2008) Differential effects of two probiotic strains with different bacteriological properties on intestinal gene expression, with special reference to indigenous bacteria. FEMS Immunol Med Microbiol 52, 69-77.

54. Kobayashi T, Kato I, Nanno M, et al. (2010) Oral administration of probiotic bacteria, Lactobacillus casei and Bifidobacterium breve, does not exacerbate neurological symptoms in experimental autoimmune encephalomyelitis. Immunopharmacol Immunotoxicol 32, 116-124.

55. Matsumoto S (2008) Anti-inflammatroy effects of probiotic Lactobacillus casei strain Shirota in chronic intestinal inflammatory disorders. Int $J$ Probiotics Prebiotics 3, 149-152.

56. Pena JA \& Versalovic J (2003) Lactobacillus rhamnosus GG decreases TNF-alpha production in lipopolysaccharide-activated murine macrophages by a contact-independent mechanism. Cell Microbiol 5, 277-285.

57. Pessi T, Sutas Y, Hurme H, et al. (2000) Interleukin-10 generation in atopic children following oral Lactobacillus rhamnosus GG. Clin Exp Allergy 30, 1804-1808.

58. Isolauri E, Arvola T, Sutas Y, et al. (2000) Probiotics in the management of atopic eczema. Clin Exp Allergy 30, $1604-1610$.

59. Kalliomaki M, Salminen S, Arvilommi H, et al. (2001) Probiotics in primary prevention of atopic disease: a randomised placebo-controlled trial. Lancet 357, 1076-1079.

60. Viljanen M, Savilahti E, Haahtela T, et al. (2005) Probiotics in the treatment of atopic eczema/dermatitis syndrome in infants: a double-blind placebo-controlled trial. Allergy $\mathbf{6 0}$, 494-500.

61. Kukkonen K, Kuitunen M, Haahtela T, et al. (2010) High intestinal IgA associates with reduced risk of IgE-associated allergic diseases. Pediatr Allergy Immunol 21, 67-73.

62. de Jonge JD, Ezendam J, Knippels LMJ, et al. (2008) Lactobacillus casei Shirota does not decrease the food allergic response to peanut extract in Brown Norway rats. Toxicology 249, 140-145.

63. Kopp MV, Hennemuth I, Heinzmann A, et al. (2008) Randomized, double-blind, placebo-controlled trial of probiotics for primary prevention: no clinical effects of Lactobacillus GG supplementation. Pediatrics 121, E850-E856.

64. Rose CE, Sung SSJ \& Fu SM (2003) Significant involvement of CCL2 (MCP-1) in inflammatory disorders of the lung. Microcirculation 10, 273-288.

65. Steensberg A, Fischer CP, Keller C, et al. (2003) IL-6 enhances plasma IL-1ra, IL-10, and cortisol in humans. Am J Physiol Endocrinol Metab 285, E433-E437. 